\title{
PERANCANGAN BUKU POP-UP CERITA RAKYAT DARI JAWA TIMUR UNTUK MENGENALKAN NILAI MORAL BAGI ANAK USIA 9-11 TAHUN
}

\author{
Angga Hendrawan ${ }^{1}$ \\ Rony Siswo Setiaji ${ }^{1}$ \\ Lifan Sugiharto ${ }^{1}$ \\ Instut Informatika Indonesia, Surabaya ${ }^{I}$ \\ research@anggahendrawan.com
}

\begin{abstract}
Abstrak
Saat ini industri hiburan didominasi oleh konten yang berasal dari luar negeri misalnya permainan, film dan komik, karena kondisi ini maka keberadaan konten-konten lokal termasuk cerita rakyat mulai tersisih. Tersisihnya cerita rakyat menjadi suatu permasalahan karena anakanak mulai menjauh dari nilai moral di daerah setempat, hal ini perlu direspon dengan menyediakan media yang sesuai untuk mengenalkan cerita rakyat kepada anak-anak, salah satunya melalui buku ilustrasi. Perancangan buku ilustrasi dilakukan dengan mempelajari keberadaan cerita rakyat di Provinsi Jawa Timur dan menerapkan metode desain thinking yang diajukan oleh Gavin Ambrse dan Paul Harris, terdapat tujuh tahapan yang terdapat di dalam metode ini, yaitu: 1) define, 2) research, 3) ideate, 4) prototype, 5) select, 6) implement, 7) learn.

Perancangan ini menghasilkan tiga buku ilustrasi cerita rakyat dari Jawa Timur dengan menerapkan teknik pop-up. Judul dari ketiga buku dirancang adalah "Kisah Cerita Banyuwangi", "Kisah Cerita AndeAnde Lumut", dan "Kisah Cerita Sawunggaling". Teknik Popup digunakan untuk meningkatkan daya tarik buku bagi anak-anak.
\end{abstract}

Kata kunci: cerita rakyat, buku, ilustrasi, pop-up

\begin{abstract}
Currently the entertainment industry is dominated by content originating from abroad such as games, films and comics, because of this condition the existence of local content including folklore began to be excluded. The exclusion of folklore becomes a problem because children begin to move away from moral values in the local area, this needs to be responded to by providing appropriate media to introduce folklore to children, one of which is through illustrated books.

The illustration book design is done by studying the existence of folklore in East Java Province and applying the thinking design method proposed by Gavin Ambrse and Paul Harris, there are seven
\end{abstract}


stages contained in this method, namely: 1) define, 2) research, 3) ideate ,4) prototype, 5) select, 6) implement, 7) learn.

This design produced three illustrated books on folklore from East Java by applying pop-up techniques. The titles of the three books designed are "Story of Banyuwangi Story", "Story of Ande-Ande Lumut Story", and "Story of Sawunggaling Story". Popup technique is used to increase the attractiveness of books for children.

Key words: single word or combination of words that are important, specific, or representative.

\section{PENDAHULUAN}

Indonesia merupakan suatu negara kepulauan dengan sejumlah kebudayaan yang tersebar di sebagian besar wilayahnya. Setiap kebudayaan dipraktikkan dalam wujud tradisi yang dilakukan oleh kelompok masyarakat terkait untuk mengekspresikan nilai-nilai luhur. Salah satu bentuk tradisi yang terdapat di dalam kebudayaan lokal yaitu berupa cerita rakyat. Cerita rakyat merupakan suatu tradisi lisan yang diwariskan oleh nenek moyang untuk mengajarkan nilai-nilai luhur termasuk nilai moral kepada generasi penerus melalui penuturan suatu kisah. Cara penuturan digunakan hingga saat ini oleh sebagian kelompok masyarakat, namun sayangnya cara seperti ini semakin ditinggalkan karena perubahan zaman dan masuknya konten-konten luar negeri.

Nenek moyang menyampaikan cerita rakyat secara lisan karena pada masa lampau kemampuan menulis relatif terbatas, sayangnya dengan penyampaian secara lisan, cerita rakyat berpotensi untuk memudar karena tidak setiap orang pada saat ini mau ataupun mampu mengingat setiap detailnya [2]. Perkembangan teknologi memungkinkan sebuah cerita rakyat disampaikan melalui beragam media, termasuk media cetak. Melalui media cetak suatu cerita rakyat dapat disebarluaskan ke kalangan yang lebih luas sekaligus menjadi upaya konservasi agar detail-detail dapat terjaga.

Sebagian besar cerita rakyat di Indonesia telah diterbitkan dalam bentuk buku dengan tampilan dua dimensi. Ditengah munculnya arus konten budaya luar negeri yang masuk, buku-buku cerita rakyat perlu memiliki nilai lebih yang menjadi daya tarik ketika dipasarkan. Salah satu teknik yang dapat digunakan untuk meningkatkan daya tarik buku cerita rakyat adalah dengan menerapkan 
teknik popup. Melalui teknik pop-up sebuah buku akan memiiliki bagian-bagian yang bergerak ketika membuka halaman buku dibuka. Melalui penerapan teknik pop-up maka sebuah buku akan menghasilkan objek-objek yang berkesan tiga dimensi dan memiliki efek pergerakan.

Berdasarkan uraian permasalahan tersebut maka perlu dilakukan upaya meningkatkan daya tarik generasi muda terhadap cerita rakyat, dengan demikian nilai-nilai luhur termasuk nilai moral dapat dikenalkan dan diturunkan dari generasi ke generasi. Salah satu upaya yang dapat dijalankan yaitu melalui perancangan media buku ilustrasi dengan menerapkan teknik pop-up. Buku ilustrasi pop-up mengangkat judul cerita rakyat yang berasal dari Provinsi Jawa Timur. Terdapat tiga judul yang diangkat dalam perancangan ini, yaitu cerita rakyat tentang kisah Banyuwangi, Ande-Ande Lumut dan Sawunggaling. Rumusan permasalahan berdasarkan latar belakang adalah: bagaimana merancang buku pop-up yang dapat mengenalkan nilai moral melalui cerita rakyat bagi anak usia 9-11 tahun?

\section{METODE PENELITIAN}

Perancangan ini dilakukan dengan menerapkan metode design thinking yang diajukan oleh Gavin Ambrse dan Paul Harris [1]. Di dalam metode Design Thinking terdapat 7 (tujuh) tahapan yang terdiri dari: 1) define, 2) research, 3) ideate, 4) prototype, 5) select, 6) implement, 7) learn. Berikut ini adalah bagan yang menggambarkan penggunaan metode design thinking pada proses perancangan ini: 


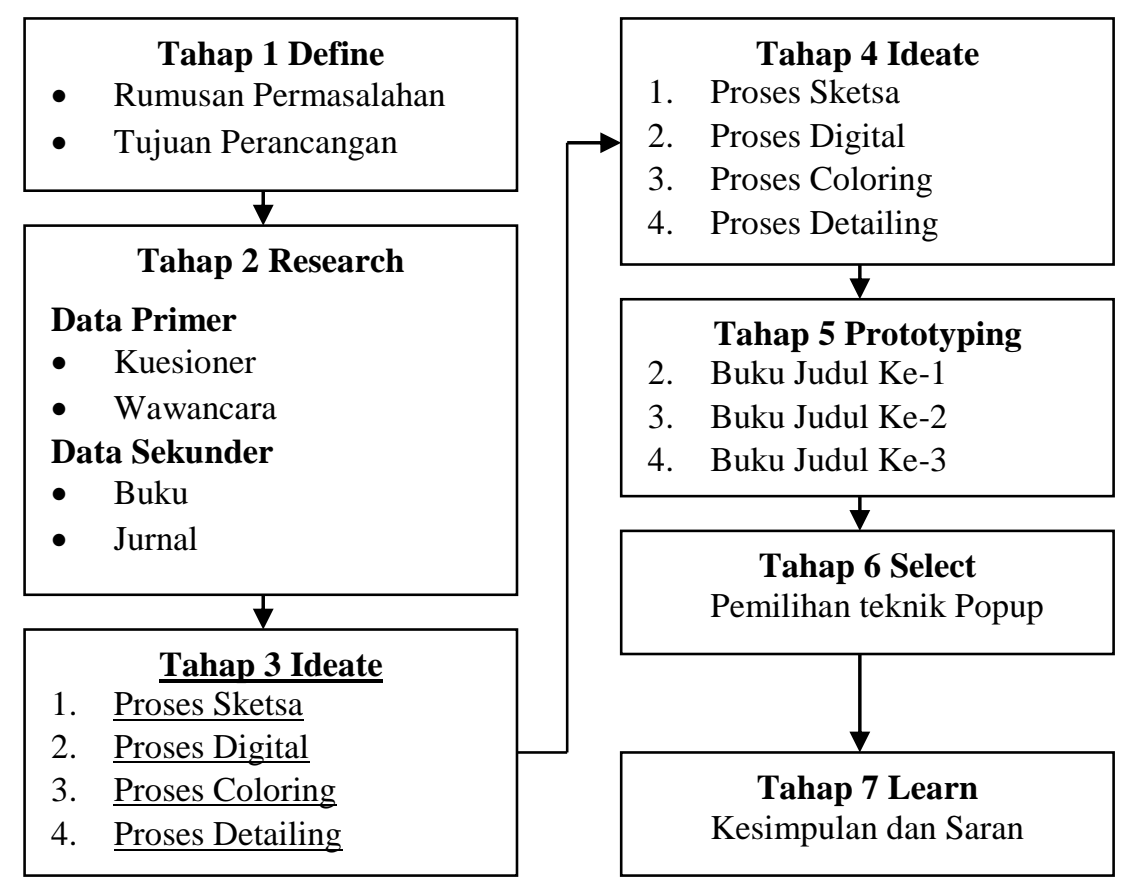

Bagan 1. Metode Perancangan

\section{HASIL DAN PEMBAHASAN}

Tahapan pertama yang dilakukan dalam proses perancangan ini adalah merumuskan permasalahan beserta tujuannya. Rumusan permasalahan yang di susun berdasarkan uraian latar belakang adalah "bagaimana merancang buku ilustrasi pop-up yang dapat mengenalkan nilai moral melalui cerita rakyat kepada anak usia 9-11 tahun?”. Tujuan perancangan ini adalah menghasilkan buku ilustrasi pop-up cerita rakyat untuk mengenalkan cerita rakyat kepada usia 9-11 tahun.

Tahapan kedua dilakukan dengan melakukan pengumpulan data, baik data primer maupun sekunder. Pengumpulan data primer dilakukan melalui teknik wawancara dan kuesioner, wawancara dilakukan dengan narasumber seorang budayawan dan guru Sekolah Dasar Untung Suropati Sidoarjo, selain itu pengumpulan data primer juga dilakukan dengan membagikan kuesioner kepada 100 siswa di sekolah tersebut. Narasumber dengan latar belakang budayawan menjelaskan bahwa cerita rakyat awalnya digunakan untuk memancing minat anak sehingga tertarik untuk mengikuti kegiatan pendidikan. Walaupun awalnya digunakan untuk memberi 
hiburan, cerita rakyat berkembang fungsinya sebagai media untuk menyampaikan nilai-nila, memancing semangat dan kreativitas. Narasumber dengan latar belakang guru Sekolah Dasar menjelaskan bahwa media yang ditujukan untuk anak-anak harus memiliki informasi yang sederhana, pada kelas besar penyusunan informasi dibuat mendetail, sedangkan bila terdapat struktur yang relatif rumit seperti pop-up maka diperlukan bantuan orang tua agar anak tidak kesulitan dalam menggunakannya. Hasil kuesioner menunjukkan 37\% responden tidak mengetahui cerita rakyat yang berasal dari Jawa Timur, data ini memberikan gambaran bahwa perlu upaya lebih untuk mengenalkan keberadaan cerita rakyat dari provinsi ini.

Tahapan ketiga dilakukan dengan menjalankan proses sketsa, digital, coloring dan detailing. Pada tahapan ini ditentukan elemen-elemen dari buku ilustrasi, yaitu: judul buku, pemetaan konten buku (naskah, setting, aset visual dan teknik pop-up). Ketiga buku yang dirancang diberi judul sesuai cerita rakyat yang diangkat, yaitu "Kisah Cerita Banyuwangi", "Kisah Cerita Ande-Ande Lumut" dan "Kisah Cerita Sawunggaling". Proses sketsa menggunakan bantuan pensil dan kertas untuk menuangkan ide dengan cepat tanpa dibatasi oleh ketrampilan penggunaan software. Proses digital digunakan untuk menkonversi sketsa menjadi format digital, proses ini dilakukan menggunakan alat scanning dan software Paint Tool SAI, proses coloring dan detailing juga dilakukan menggunakan software tersebut. Masing-masing buku direncanakan memiliki sejumlah 13 halaman untuk menghindari ketebalan buku berlebih yang dapat menyebabkan resiko kerusakan.
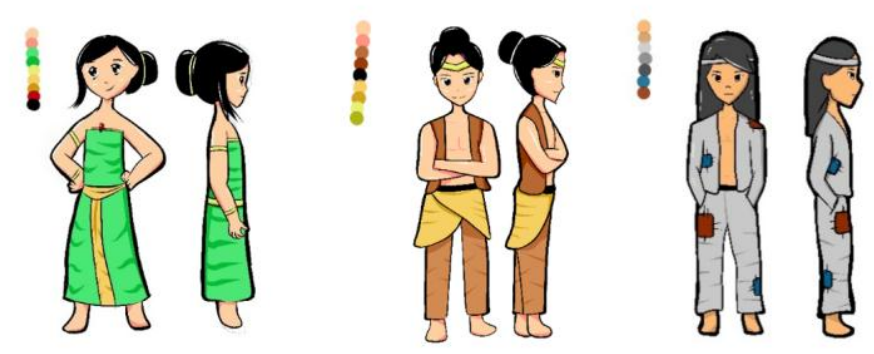

\section{Gambar 1. Karakter Cerita Banyuwangi}

Sumber: Dokumentasi Penulis 

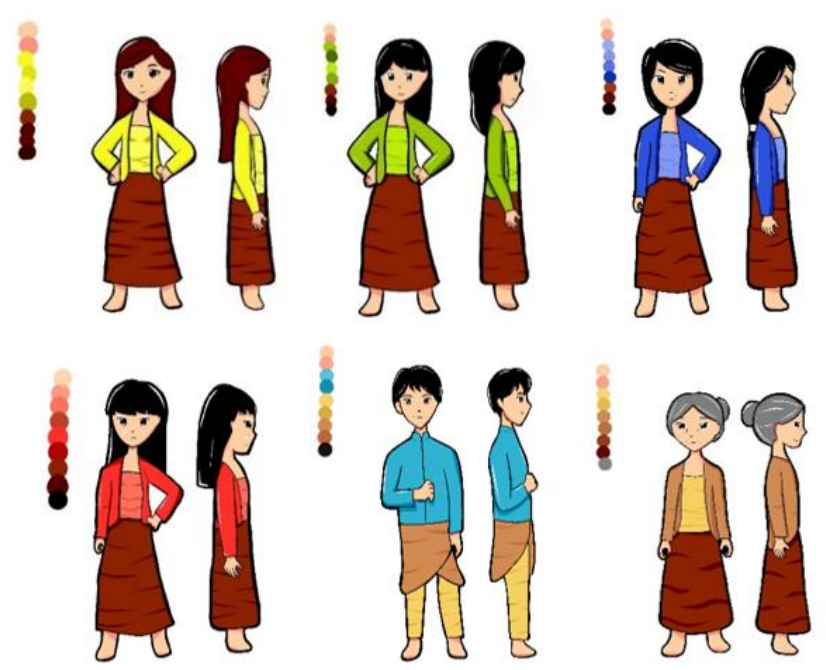

Gambar 2. Karakter Cerita Ande-Ande Lumut

Sumber: Dokumentasi Penulis

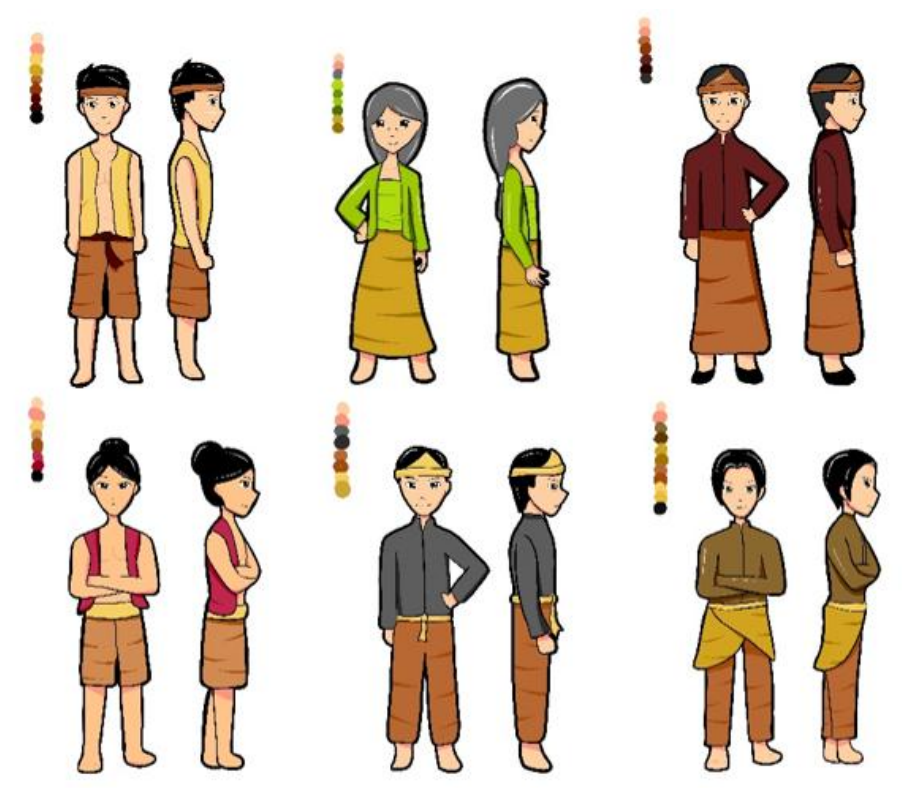

Gambar 3. Karakter Cerita Sawunggaling

Sumber: Dokumentasi Penulis 
Tahapan keempat dilakukan dengan menerapkan teknik pop-up pada halaman buku yang telah dirancang pada bagian sebelumnya. Teknik pop-up yang digunakan pada buku antara lain: v-folding, m-folding, pull-strips, parallel fold, twisting, airplane, moving arm. Pembuatan prototipe dilakukan dengan halaman-halaman yang terpisah untuk memudahkan penggantian apabila suatu teknik tidak bekerja.

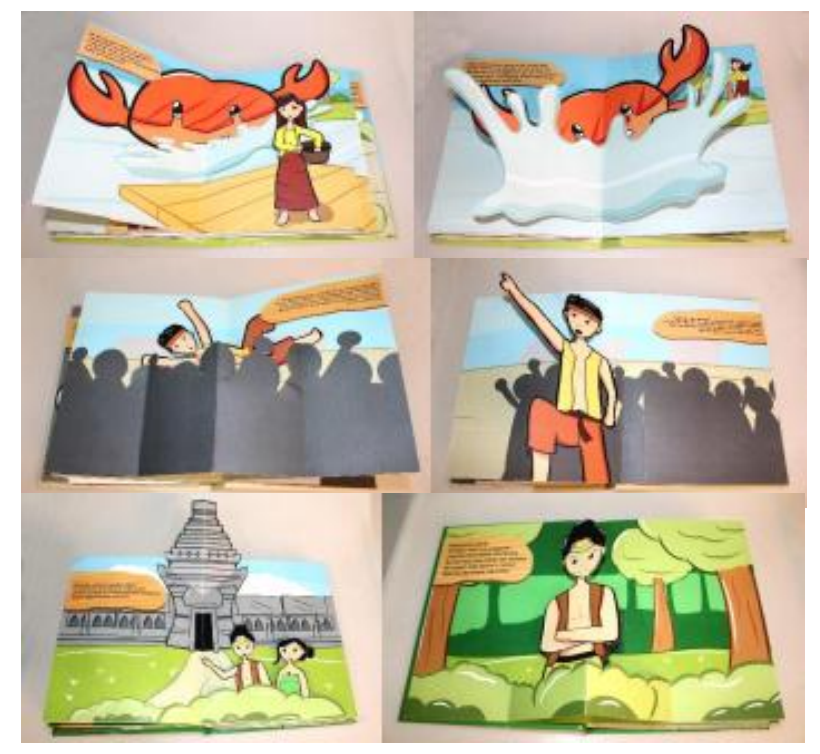

Gambar 4. Contoh Teknik Pop-up

Sumber: Dokumentasi Penulis

Tahapan kelima dilakukan untuk menentukan gaya ilustrasi dari tokoh-tokoh dan latar belakang cerita. Tahapan seleksi juga dilakukan untuk memilih teknik popup yang dapat bekerja dengan baik dan mendukung penyampaian konten pada halaman buku. Tahapan ini dilakukan sejak tahapan ketiga, yaitu menentukan setiap aset visual yang telah melalui proses digital.

Tahapan keenam dilakukan dengan mengimplementasikan teknik pop-up yang bekerja dengan baik pada semua halaman buku. Pada tahapan ini halaman-halaman buku dijadikan satu melalui teknik penjilidan hard cover sehingga buku tetap solid dan terhindar dari perubahan bentuk ekstrim. 


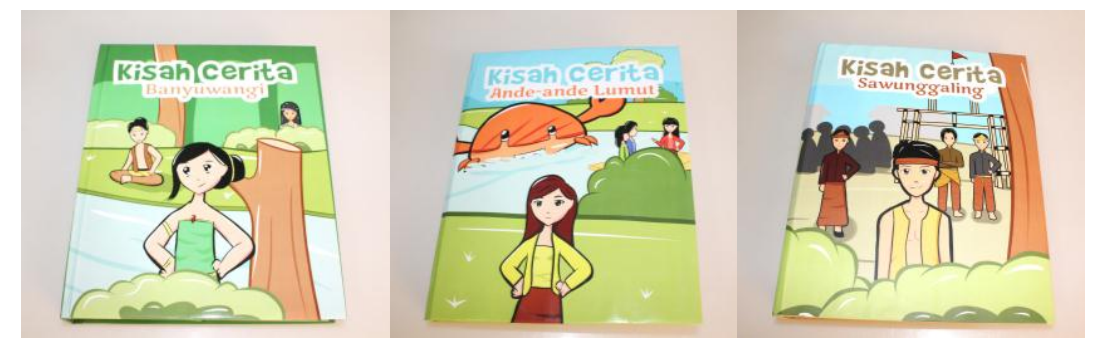

Gambar 5. Tampilan Akhir Buku Ilustrasi

Sumber: Dokumentasi Penulis

Tahapan terakhir dilakukan dengan mempelajari kondisi dan kinerja buku setelah selesai diproses. Sebagian besar teknik pop-up dapat bekerja dengan baik ketika halaman-halaman buku sudah disatukan (dijilid), namun demikian masih terdapat beberapa teknik pop-up yang tidak bekerja dengan baik. Permasalahan ini terjadi karena tekanan pada tiap-tiap halaman buku berubah ketika sudah dijilid, sehingga berpengaruh terhadap kondisi kertas dan struktur pop-up.

\section{SIMPULAN DAN SARAN}

\section{Simpulan}

Pengumpulan data memberikan gambaran bahwa cerita rakyat dapat digunakan sebagai media menyampaikan nilai-nilai luhur dengan cara yang menarik. Pada saat ini cerita rakyat mulai tergeser akibat oleh keberadaan kontenkonten hiburan baik dari dalam negeri dan luar negeri. Dengan adanya persaingan tersebut maka perlu adanya upaya kreatif sehingga target market tertarik dengan buku cerita rakyat dari Jawa Timur, dengan demikian tujuan pengenalan nilai moral kepada anak-anak dapat tercapai. Strategi yang digunakan untuk menciptakan daya tarik dilakukan melalui penggunaan teknik pop-up, terdapat beragam teknik pop-up yang digunakan untuk memberikan variasi dan memperkuat jalan cerita di tiap halaman. Perancangan menghasilkan capaian sesuai tujuan awal berupa 3 (tiga) buku pop-up yang masing-masing berjudul "Kisah Cerita Banyuwangi", "Kisah Cerita Ande-Ande Lumut" dan "Kisah Cerita Sawunggaling". Setelah dievaluasi, terdapat beberapa teknik popup yang tidak berjalan dengan baik setelah halaman-halaman buku mulai disatukan (dijilid), hal ini terjadi karena terdapan bentuk objek yang kurang sesuai dengan teknik popup 
yang dipilih. Kegagalan fungsi pop-up ini belum terlihat pada saat diuji dalam halaman-halaman terpisah, namun permasalahan ini baru diketahui ketika halamanhalaman telah dijilid.

\section{Saran}

Permasalahan utama yang terjadi pada proses perancangan buku pop-up adalah terdapat kegagalan kinerja pada salah satu teknik pop-up ketika halamanhalaman buku mulai dijilid. Terdapat proses yang terlewatkan pada proses pengujian prototipe, teknik pop-up seharusnya diuji ketika halaman-halaman buku disatukan (dijilid) bukan sebatas pengujian terhadap halaman-halaman terpisah. Permasalahan ini memberikan gambaran bahwa perancangan sejenis berikutnya harus memperhatikan agar tahapan prototyping dilakukan menyerupai kondisi sebenarnya. Perbedaan kondisi pengujian akan berimbas pada tahap implementasi yang akan memberikan hasil diluar ekpektasi.

\section{DAFTAR PUSTAKA}

Ambrose, Gavin dan Harris, Paul. 2010. Design Thinking. Switzerland

Kristanto, M. 2014. "Pemanfaatan Cerita Rakyat sebagai Penanaman Etika untuk Membentuk Pendidikan Karakter Bangsa". Mimbar Sekolah Dasar. Vol.1 No.1 2014. Hal 59-64. 